\title{
Severe mortality of a population of threatened Agassiz's desert tortoises: the American badger as a potential predator
}

\author{
Patrick G. Emblidge ${ }^{1,2, *}$, Ken E. Nussear ${ }^{3}$, Todd C. Esque ${ }^{2}$, Christina M. Aiello ${ }^{1,2}$, \\ Andrew D. Walde ${ }^{4}$ \\ ${ }^{1}$ Department of Biology, 208 Mueller Laboratory, The Pennsylvania State University, University Park, PA 16802, USA \\ ${ }^{2}$ U.S. Geological Survey, Western Ecological Research Center, Las Vegas Field Station, 160 N. Stephanie Street, Henderson, \\ NV 89074, USA \\ ${ }^{3}$ Department of Geography, University of Nevada, 1664 N. Virginia Street, Reno, NV 89557, USA \\ ${ }^{4}$ Walde Research \& Environmental Consulting, 8000 San Gregorio Road, Atascadero, CA 93422, USA
}

\begin{abstract}
In the Mojave Desert of the southwestern United States, adult Agassiz's desert tortoises Gopherus agassizii typically experience high survival, but population declines associated with anthropogenic impacts led to their listing as a threatened Species under the US Endangered Species Act in 1990. Predation of adult tortoises is not often considered a significant threat as they are adapted to deter most predation attempts. Despite these adaptations, some populations have experienced elevated mortality attributed to predators, suggesting that predation pressure may occasionally increase. During the tortoise activity seasons of 2012 and 2013, we observed unsustainably high mortality in 1 of 4 populations of adult desert tortoises (22 and $84 \%$, respectively) in the western Mojave Desert in the vicinity of Barstow, CA. Photographic evidence from trail cameras and examination of carcass condition suggest that American badgers Taxidea taxus-a sometimes cited but unconfirmed predator of adult tortoises - may have been responsible for some of the mortality observed. We discuss the American badger as a plausible predator of a local tortoise population, but recommend further investigation into these events and the impacts such mortality can have on tortoise persistence.
\end{abstract}

KEY WORDS: Desert tortoise $\cdot$ Predation $\cdot$ American badger $\cdot$ Native predator

\section{INTRODUCTION}

Ensuring that populations of threatened and endangered species maintain high survivorship is of critical concern for wildlife managers. High adult survivorship is a characteristic life history trait of many long-lived species (Congdon et al. 1994), and chronic increases in adult mortality (particularly in females) may destabilize populations and increase the likelihood of extinction (Doak et al. 1994).

${ }^{*}$ Corresponding author: patrickemblidge@gmail.com
Agassiz's desert tortoise Gopherus agassizii is a late-maturing, long-lived species protected under the US Endangered Species Act across its range in the Mojave Desert of the southwestern United States (USFWS 1994). Individuals reach sexual maturity around 15 yr (Germano 1994) and can live to $45 \mathrm{yr}$ in the wild (Medica et al. 2012). Adult desert tortoises normally have high annual survival rates (98\%) (USFWS 1994) and are well adapted to avoid predation due to their morphol-

(C) The authors 2015. Open Access under Creative Commons by Attribution Licence. Use, distribution and reproduction are unrestricted. Authors and original publication must be credited.

Publisher: Inter-Research · www.int-res.com 
ogy, behavior, and burrow use (Woodbury \& Hardy 1948).

Burrows are important features of the desert tortoises' environment, providing shelter from extreme temperatures, aridity, and predators, and act as sites of conspecific interaction and nesting (Woodbury \& Hardy 1948, Turner et al. 1986, Bulova 1994, Rostal et al. 1994). Tortoises spend the majority of the year inactive in burrows or dens and are surface active primarily in the spring and late summer when forage and occasional water are available and high ambient temperatures do not preclude activity (Nagy \& Medica 1986). Tortoises dig burrows by alternately scraping at the end of the tunnel with each forelimb and pushing loose soil out through the entrance (Woodbury \& Hardy 1948), resulting in a tunnel up to a few meters long of similar width and height as the individual tortoise and a raised 'apron' at the mouth of the burrow. Tortoises occupy multiple burrows throughout the year and a single burrow may be used by multiple tortoises, either synchronously or asynchronously (Bulova 1994).

Common ravens Corvus corax, coyotes Canis latrans, and mountain lions Puma concolor have been implicated as significant predators on Agassiz's tortoises (Peterson 1994, Boarman 2002, Medica \& Greger 2009, Esque et al. 2010), and high mortality events, often attributed to drought or a combination of drought and predation, have been documented since the 1980s (Turner et al. 1984, Germano \& Joyner 1988, Peterson 1994, Longshore et al. 2003, Esque et al. 2010). Increased mortality can be caused by a combination of anthropogenic and natural factors, but specific causes of mortality need further clarification in order to effectively address population declines. In this Note we document a seemingly high level of predation in one of 4 populations and present evidence that suggests American badgers Taxidea taxus may be a locally important predator of desert tortoises.

\section{MATERIALS AND METHODS}

In April 2012 we began studies of Agassiz's desert tortoise populations in the Western Mojave Desert at 4 sites on and around the US Army Fort Irwin National Training Center (NTC),
San Bernardino County, CA, USA (Fig. 1). The geomorphology of the area is open desert flats consisting of deep Quaternary alluvium interspersed with low hills and ridges of Miocene to Pleistocene conglomerate rock. The elevation of the sites ranges from 600 to $1000 \mathrm{~m}$ with vegetation consisting of typical creosotebursage (Larrea tridentate and Ambrosia dumosa) desert scrub (Turner 1994). Each site covered approx. 900 ha and all sites were within $35 \mathrm{~km}$ of each other. Our initial study populations consisted of adult tortoises (carapace length $>185 \mathrm{~cm}$ ) incorporated from previous research. As the research project progressed we incorporated additional adult tortoises opportunistically encountered and removed transmitters from tortoises deemed unnecessary for our design requirements. Sex was not considered when acquiring or removing animals, resulting in a naturally representative sex ratio of our sample population at each site. All study tortoises were equipped with $15 \mathrm{~g}$ radio transmitters (model RI-2B, Holohil Systems) attached to the carapace using epoxy putty and were located at least monthly, with a mean of $10 \mathrm{~d}$ between relocations during the active season (April through to October). Animals that remained alive at the end of 2012 were retained for 2013 .

During May to September 2012, and April to October 2013, we observed high levels of mortality at Site 4

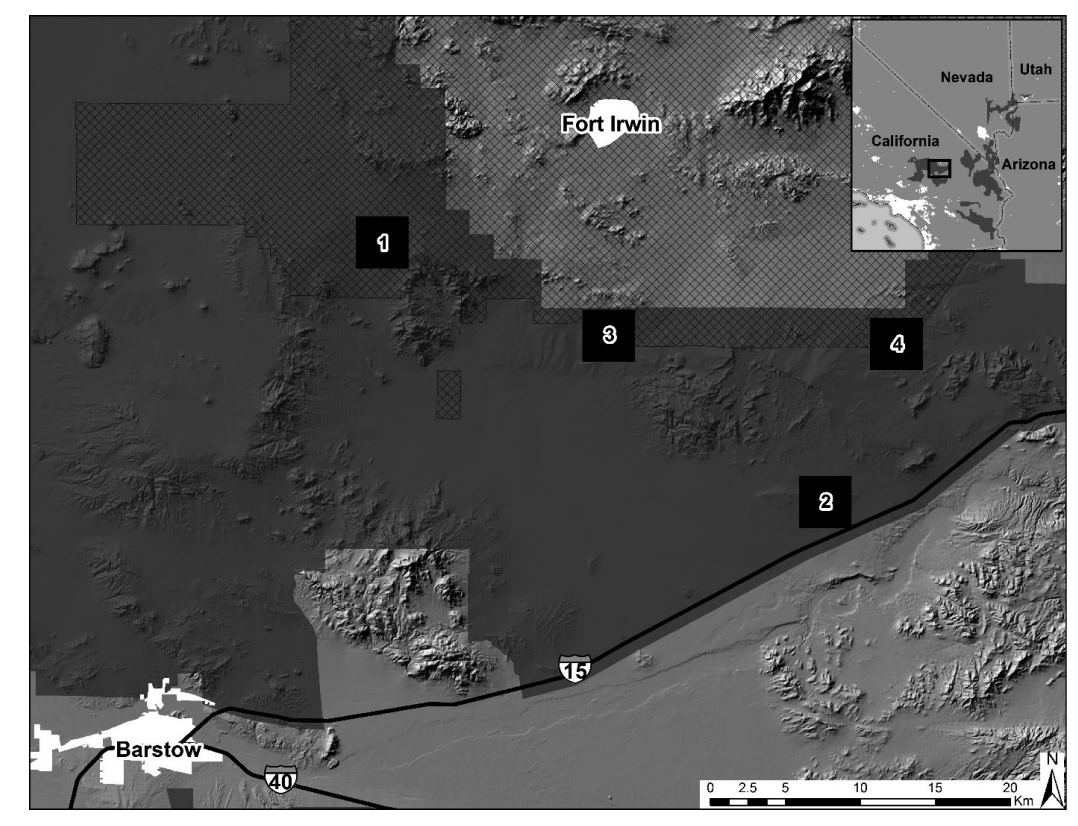

Fig. 1. Four study sites (ca. 900 ha each; solid black squares) in the Mojave Desert of San Bernardino County, CA, USA. Site 4 experienced significant mortality of Agassiz's desert tortoise Gopherus agassizii in 2012-2013. White= urban centers, dark grey = areas designated as critical habitat for Agassiz's desert tortoise, cross hatching $=$ Fort Irwin National Training Center 
(Fig. 1). This high mortality site was located about $55 \mathrm{~km}$ east-northeast of Barstow, on the southeast corner of the NTC and adjacent lands administered by the Bureau of Land Management within the US Department of the Interior. Each time we encountered a tortoise carcass we recorded the location, body position, damage to the carcass, evidence of predation/scavenging, and took photos to document the condition of the carcass. We compared carcass observations to anecdotal descriptions of tortoise mortality at this site during previous studies and found similarities. On a couple of occasions, previous researchers observed ravens pecking at the posterior area between the plastron and carapace of an overturned adult tortoise, though the circumstances leading to this situation were never observed (A. D. Walde pers. obs.). Based on these past observations, and our new observations of carcass damage and large bird tracks and/or scats near 3 carcasses, we suspected ravens were responsible for some tortoise mortality.

In response to these observations, Wildlife Services (US Department of Agriculture) removed 10 adult ravens from Site 4 in July 2013. Despite raven control, tortoise mortality continued, and in response we began monitoring burrow entrances of live tortoises to detect ravens or other unconsidered predators. We installed motion-triggered trail cameras (Little Acorn Outdoors) at burrows currently occupied by tortoises, either placed on the ground ca. $3 \mathrm{~m}$ from the burrow entrance or on PVC stakes $1 \mathrm{~m}$ above ground at the same distance. Cameras were relocated or removed when a tortoise moved to a different burrow or was found dead. Altogether, 10 of the 11 surviving tortoises and 29 unique burrows (1 to 4 per tortoise) were monitored for a total of 1107 camera-days from July 2013 through March 2014.

\section{RESULTS}

We tracked a total of 155 adult Agassiz's desert tortoises during this study. One hundred initial study animals plus 40 additional individuals were monitored in 2012. Eight tortoises died and we ceased monitoring 24 unnecessary tortoises, whose fates are unknown. Overall, 108 study animals from 2012 and 15 additional individuals were monitored in 2013. We do not report the fate of tortoises that were not tagged with radio transmitters. The condition of all tortoises was confirmed during or at the end of each year of study by either encountering a carcass or observing the tortoise emerge from its overwintering burrow the following spring. No transmitters were lost during this study. Annual mortality was $<5 \%$ for Sites 1-3 in both years, except for a period of suspected canid predation in 2013 at Site 1 (17.9\% mortality). At Site 4 (the high mortality site), we observed 6 of 27 monitored tortoises dead in 2012 and 21 of 25 monitored tortoises dead in 2013 (Table 1). The dead tortoises ranged in carapace length from 198 to $283 \mathrm{~mm}$ and in mass from 1.4 to $4.5 \mathrm{~kg}$.

We documented similar body position, damage, and microsite condition among carcasses encountered at Site 4 (Fig. 2), which differed from carcasses at other sites. Tortoises were almost always found flipped on their carapaces (24 of 27), often inside a burrow, or in the open near a burrow. Thirteen carcasses were found in burrows or pallets (small excavations that provide partial cover for tortoises), 11 were found within $30 \mathrm{~m}$ of active tortoise burrows, 2 were within $85 \mathrm{~m}$ of active tortoise burrows, and one appeared to have been dragged on its carapace about $185 \mathrm{~m}$ from a burrow. All 13 carcasses found in burrows or pallets were overturned. Heads were often separated from the bodies or had damage to the flesh and vertebrae of the neck. Nineteen carcasses were decapitated, with 7 heads found next to the carcass and 12 heads absent. Eight tortoise heads were still attached or partially attached. There was almost always at least one large opening (approximately $4 \mathrm{~cm}$ wide) in the prefemoral region directly anterior to a hind limb (Fig. 2C). Forelimbs were often intact (17 of 27) and there were no discernible scratch or chew marks on any of the tortoise shells.

Of the 10 tortoises monitored with burrow cameras, 2 were found dead in the monitored burrow, one was found dead in an adjacent unmonitored burrow, and one was found dead in the open $<30 \mathrm{~m}$ from the monitored burrow. Two of the remaining tortoises were found dead in unmonitored burrows $>100 \mathrm{~m}$ from the

Table 1. Fate of radio-tagged Agassiz's desert tortoises Gopherus agassizii at the conclusion of each study year at 4 study sites in the Mojave Desert of San Bernardino County, CA, USA. Alive tortoises were confirmed by their emergence from overwintering burrows the following year and subsequently remained in the study. Tortoises were confirmed dead on the discovery of their carcass

\begin{tabular}{|c|c|c|c|c|c|c|}
\hline \multirow[b]{2}{*}{ Site } & \multicolumn{3}{|c|}{$2012-$} & \multicolumn{3}{|c|}{2013} \\
\hline & Alive & Dead & $\%$ Mortality & Alive & Dead & $\%$ Mortality \\
\hline 1 & 27 & 1 & 3.6 & 23 & 5 & 17.9 \\
\hline 2 & 29 & 0 & 0.0 & 31 & 1 & 3.1 \\
\hline 3 & 31 & 1 & 3.1 & 38 & 0 & 0.0 \\
\hline 4 & 21 & 6 & 22.2 & 4 & 21 & 84.0 \\
\hline
\end{tabular}




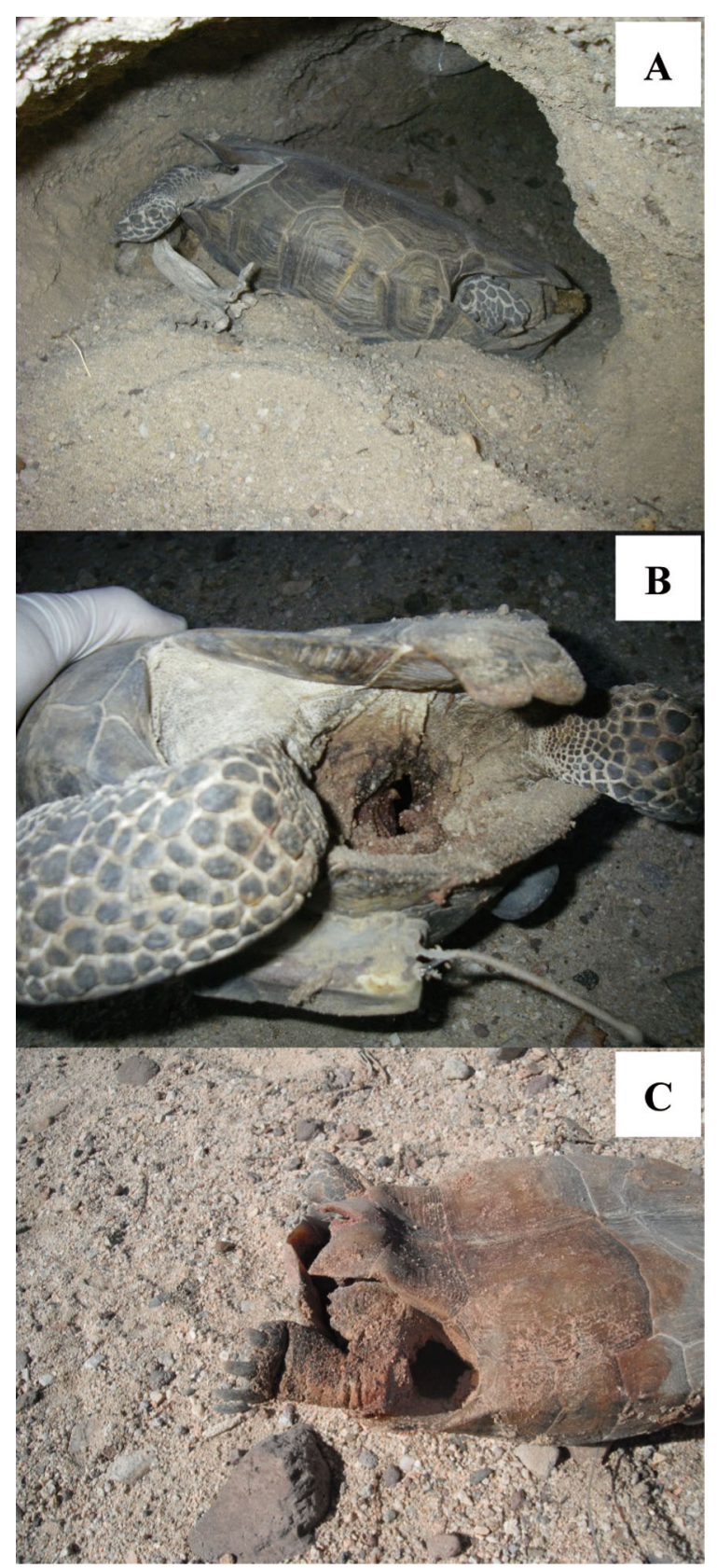

Fig. 2. Condition of the adult Agassiz's desert tortoise Gopherus agassizii carcasses observed at Site 4 in the Mojave Desert of San Bernardino County, CA, USA. Dead tortoises were often found (A) upside-down in or near a burrow, (B) partially to fully decapitated, and $(\mathrm{C})$ with a large hole in the prefemoral region anterior to a hind limb. Photographed tortoises had carapace lengths of $240 \mathrm{~mm}, 270 \mathrm{~mm}$, and $280 \mathrm{~mm}$, respectively

nearest camera and 4 were still alive at the end of the study. A description of each of the 4 cases where carcasses were discovered in or near monitored burrows follows.
Tortoise no. 1 was found dead in the monitored burrow $14 \mathrm{~d}$ after it was last observed there alive. The carcass was upside down, with the head removed (but found within the burrow), and in fairly advanced decay. Four days after the camera was placed at the burrow the tortoise was photographed departing, then returning to the burrow, and appeared to have normal posture and condition. Two days later a badger was photographed approaching the burrow and immediately began digging (Fig. 3). After an hour of digging and activity at the mouth of the burrow the badger left and was not seen to return.

Tortoise no. 2 was found dead in the monitored burrow, $6 \mathrm{~d}$ after it was last observed there alive. The carcass was found upside-down $\sim 70 \mathrm{~cm}$ deep within the burrow. Its head was nearly torn off and the carcass was very fresh, with still-wet viscera found in the burrow and at the entrance. The soil inside and next to the burrow was disturbed, but no discernible tracks were observed. Over 4000 photos, triggered mostly by plant movement, were taken over these $6 \mathrm{~d}$ and a single photo of interest shows a stocky mammal (unconfirmed badger) approaching the burrow $6 \mathrm{~h}$ prior to discovery of the carcass.

Tortoise no. 3 was found dead in a burrow $2 \mathrm{~m}$ away from the monitored burrow, $22 \mathrm{~d}$ after it was last seen there alive. The carcass was upside down, decapitated, and it was in advanced decay. Twenty-one days before the carcass was discovered, photographs show a tortoise leaving the monitored burrow in the

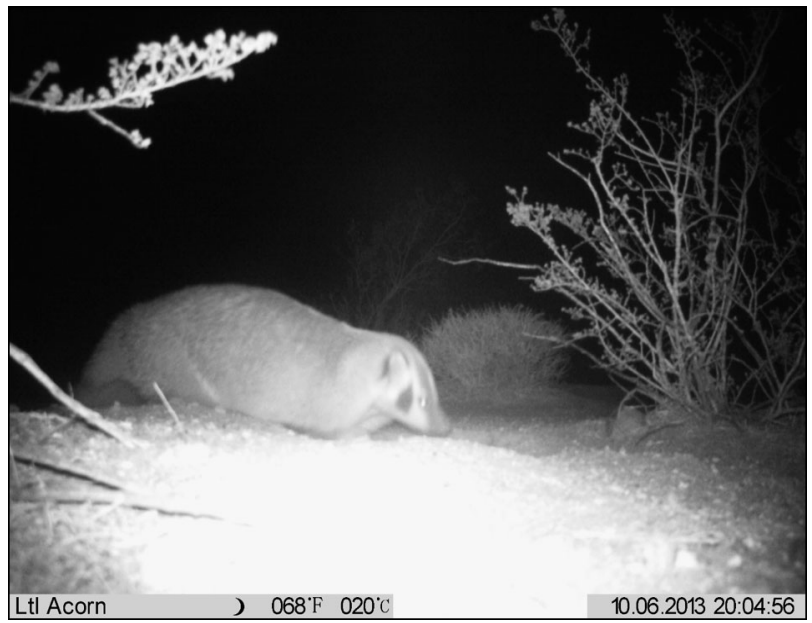

Fig. 3. An American badger Taxidea taxus photographed at the mouth of an occupied Agassiz's desert tortoise Gopherus agassizii burrow in the Mojave Desert of San Bernardino County, CA, USA. The badger was sporadically digging at the burrow for an hour. The tortoise was found dead in this burrow $8 \mathrm{~d}$ later and no other potential predators were photographed 
direction of the location where it was later found dead. Eleven days later a badger is seen investigating the monitored burrow, also heading in the direction of the location where the carcass was discovered.

Tortoise no. 4 was found dead above ground $27 \mathrm{~m}$ from the monitored burrow, where it had last been seen alive $6 \mathrm{~d}$ earlier. The carcass was overturned with the head nearly detached, and dried viscera nearby. The camera captured images of a badger visiting the burrow on 2 occasions, 4 and $5 \mathrm{~d}$ prior to discovery of the carcass.

The only observation of a potential predator of adult tortoises other than a badger at any of these locations was a fox (likely Vulpes microtis) that was photographed walking past, but not inspecting, the burrow of tortoise no. 4 between badger visits. None of the deployed cameras recorded ravens in the immediate vicinity of a tortoise burrow. However, the cameras did record turkey vultures Cathartes aura, a red-tailed hawk Buteo jamaicensis, and many songbirds, suggesting that if ravens had visited the burrow they would have been recorded.

\section{DISCUSSION}

In 2012 and 2013 we observed significant mortality (22 and $84 \%$, respectively) on a sample population of adult desert tortoises at one of 4 study sites in the Western Mojave Desert. The degree of mortality observed at this site far surpasses the highest level reported to date for a wild population (43.5\%) (Esque et al. 2010) and poses a serious threat to the persistence of the local tortoise population.

Although we do not have direct observations of badgers killing adult tortoises our observations suggest they may be responsible for at least some of the mortality observed. On 2 occasions we have photographic evidence of a badger visiting a burrow between the time a tortoise was last recorded there alive and the time it was found dead in the burrow. Although this observation alone does not confirm predation, the lack of evidence of other potential predators and the degree of carcass decay consistent with the timing of badger visits suggests that badgers were likely responsible. Observations of badgers in the vicinity of 2 other tortoise mortalities and the consistency of carcass condition across this high-mortality site may indicate badger involvement in additional deaths.

American badgers have been mentioned as potential predators on adult tortoises (Luckenbach 1982, Ernst \& Lovich 2009), but to our knowledge, this report describes the first mortality event suggesting badger involvement. Although little is known about badger ecology in the deserts of the American Southwest, studies of badgers in other parts of their range and other Mustelid species suggest that predation on desert tortoises should not be surprising. Multiple species of otters are known to consume turtles (Brooks et al. 1991, Lanszki et al. 2006, Ligon \& Reasor 2007, Platt \& Rainwater 2011), and European badgers Meles meles have depredated Hermann's tortoises Testudo hermanni in reintroduction projects in both Spain and France (Bertolero et al. 2007, Caron et al. 2013).

American badgers specialize on fossorial mammalian prey but may increase prey diversity during periods of low preferred prey availability (Messick \& Hornocker 1981). The abundance of small mammals in the Mojave Desert can fluctuate with the availability of winter precipitation, which influences the abundance of annual vegetation that provides their forage (Beatley 1969). This variability in small mammal populations during precipitation cycles has been implicated in many observations of elevated coyote predation on Agassiz's tortoises (Woodbury \& Hardy 1948, Peterson 1994, Esque et al. 2010). Indeed, a National Oceanic and Atmospheric Administration weather station located $40 \mathrm{~km} \mathrm{SW}$ of our high mortality site received well under $50 \%$ of the $30 \mathrm{yr}$ normal winter precipitation during the $2 \mathrm{yr}$ in which we suspect badger predation, potentially providing the stimulus for badgers to incorporate tortoises into their diet.

We caution that alternative explanations for this high mortality should be considered. What we assume to be predation of healthy tortoises could in fact be scavenging following mortality from disease or drought stress. Upper respiratory tract disease and drought can have serious impacts on adult tortoise survival (Jacobson et al. 1991, Longshore et al. 2003), though we observed few indications these stressors were involved. Tortoises were tracked on average every $10 \mathrm{~d}$ by a team of researchers intimately familiar with assessing physical condition and identifying clinical signs of disease in Agassiz's tortoise. No tortoises were observed in poor physical condition (as would be caused by drought stress) or exhibiting clinical signs of disease. Additionally, although both years of study received below average rainfall, tortoises at nearby sites experiencing similar conditions did not exhibit high mortality.

Other unobserved predators may also contribute to mortality. Larger predators such as mountain lion, coyote, and bobcat Lynx rufus are known to crush or 
gnaw on the tortoise shell and consume the head and limbs (Woodbury \& Hardy 1948, Peterson 1994, Medica \& Greger 2009). The shells of tortoise carcasses we found were all intact with no scour marks, and most limbs were also still attached, suggesting that these larger predators were not responsible for tortoise mortality. Raven predation, as initially suspected, is still a possibility and indeed evidence of large birds was associated with 3 carcasses. What we find most odd, though, is the upside-down position of decapitated carcasses within burrows. It seems likely that if an attack occurred outside a burrow by ravens or a scavenger returned a carcass to a burrow we would observe signs of such activity in the substrate or on trail cameras that exhibited sensitivity to even slight plant movement. Mortality sites lacked drag marks in the substrate leading to a carcass in a burrow, suggesting that animals found dead in burrows had died there.

Badgers are known for their ability to move large amounts of soil in pursuit of small fossorial prey, leaving behind large fan-shaped deposits outside round tunnels (Eldridge 2004). Desert tortoises also excavate large amounts of soil resulting in fan-shaped aprons and burrows that are large enough to allow a badger to enter. These features of tortoise burrows would likely allow a badger to access it without causing distinguishable alterations to the burrow or apron.

Photographic evidence and the condition and position of tortoise carcasses suggest that badgers may pose a significant localized threat, but further clarification is needed. We recommend further investigation to confirm the badger as a predator and determine the spatial and temporal scope of predation on adult tortoises in this and other parts of their range. The extent of these predation events will determine the degree of risk they present to populations and whether management actions are needed to mitigate their impacts. An important step will be to provide tortoise field researchers with a description of the carcass conditions observed here (tortoise found upside down within or near a burrow, neck heavily damaged or head removed, and openings to the body cavity in the prefemoral area). This would assist managers in identifying the frequency and location of this type of mortality and possibly lead to increased evidence of the predator(s) involved. Additionally, studies of badger ecology in the arid American Southwest would be invaluable and may clarify hunting behavior in this unique habitat.

If badgers are confirmed to be the cause of tortoise mortality, care must be taken not to consider T. taxus as a ubiquitous threat to tortoise persistence. Badgers occasionally develop idiosyncratic hunting techniques including tool-use (Michener 2004) and ambush hunting (Eads et al. 2012), but these behaviors have a low likelihood of spreading or persisting because of the solitary habits of badgers. Badgers have also been observed cohabitating both summer and winter shelters with tortoises without harming them (Germano \& Perry 2012, P. Medica pers. comm.). These features of badger behavior suggest that a single individual could be responsible for the tortoise mortality observed. However, if badger predation is determined to be a problem requiring redress, wildlife managers will face the difficult situation of attempting to reduce predation on a threatened species by a native predator where social, political, economic, and ethical considerations add complexity to the decision-making process (Goodrich \& Buskirk 1995, Minteer \& Collins 2005); this may be particularly difficult with badgers, since they are a species of special concern in California (CDFW 2014).

The life-history traits of desert tortoises: slowmaturing and long-lived, with high adult survival ( 0.98) (USFWS 1994) make them particularly sensitive to even slight increases in adult mortality (Congdon et al. 1993, Doak et al. 1994). Alarmingly, periods of high mortality appear to be increasingly common, and are threatening to alter desert tortoise population dynamics (Turner et al. 1984, Peterson 1994, Longshore et al. 2003, Esque et al. 2010, Medica et al. 2012, Zylstra et al. 2013). Although populations may occasionally be able to rebound from temporary periods of elevated mortality (Germano \& Joyner 1988, Zylstra et al. 2013), increasing intensity, frequency, and duration of mortality events, coupled with habitat loss and fragmentation and a more physiologically stressful climate (Zylstra et al. 2013, Lovich et al. 2014) pose serious threats to the persistence of tortoise populations (Brook et al. 2008). Furthermore, as tortoise populations continue to decline, stochastic predation events on small populations may have an increasingly important effect on tortoise persistence (Medica et al. 2012, Osterback et al. 2013).

Acknowledgements. We are grateful for field assistance from Andrew Berger, John Jozkowski, Jose Lopez, Margarete Walden, Rob Saulino, and countless Student Conservation Association interns. Disussions with Phil Medica and comments from 2 anonymous reviewers contributed greatly to the clarity of this manuscript. This research was supported by The National Science Foundation Ecology of Infectious Diseases grant \#1216054 and the US Department of Defense, Fort Irwin, California. All research was conducted in accordance with US Geological Survey Animal Care and Use protocols and US Fish and Wildlife Service and California De- 
partment of Fish and Game permits. Any use of trade, product, or firm names is for descriptive purposes only and does not imply endorsement by the US Government.

\section{LITERATURE CITED}

Beatley JC (1969) Dependence of desert rodents on winter annuals and precipitation. Ecology 50:721-724

$>$ Bertolero A, Oro D, Besnard A (2007) Assessing the efficacy of reintroduction programmes by modelling adult survival: the example of Hermann's tortoise. Anim Conserv $10: 360-368$

Boarman WI (2002) Reducing predation by common ravens on desert tortoises in the Mojave and Colorado Deserts. San Diego, CA

> Brook BW, Sodhi NS, Bradshaw CJA (2008) Synergies among extinction drivers under global change. Trends Ecol Evol 23:453-460

> Brooks RJ, Brown GP, Galbraith DA (1991) Effects of a sudden increase in natural mortality of adults on a population of the common snapping turtle (Chelydra serpentina). Can J Zool 69:1314-1320

Bulova SJ (1994) Patterns of burrow use by desert tortoises: gender differences and seasonal trends. Herpetol Monogr 8:133-143

Caron S, Ballouard JM, Lepeigneul O, Bonnet X (2013) Experimental translocation (re-inforcement) of the Hermann's tortoise, Var, France. In: Soorae PS (ed) Global Re-introduction Perspectives: 2013. IUCN/SSC Re-introduction Specialist Group \& Environment Agency, Abu Dhabi, p 42-46

CDFW (California Department of Fish and Wildlife, Natural Diversity Database) (2014) Special Animals List CDFW, Sacramento, CA

> Congdon JD, Dunham AE, Van Loben Sels RC (1993) Delayed sexual maturity and demographics of Blanding's turtles (Emydoidea blandingii): implications for conservation and management of long-lived organisms. Conserv Biol 7:826-833

Congdon JD, Dunham AE, Van Loben Sels RC (1994) Demographics of common snapping turtles (Chelydra serpentina): implications for conservation and management of long-lived organisms. Am Zool 34:397-408

Doak D, Kareiva P, Klepetka B (1994) Modeling population viability for the desert tortoise in the western Mojave Desert. Ecol Appl 4:446-460

Eads DA, Hague MTJ, Zoubek CG (2012) American badger (Taxidea taxus) uses covert reconnaissance to ambush a black-tailed prairie dog (Cynomys ludovicianus). Southwest Nat 57:463-464

Eldridge DJ (2004) Mounds of the American badger (Taxidea taxus): significant features of North American shrub-steppe ecosystems. J Mammal 85:1060-1067

Ernst CH, Lovich JE (2009) Turtles of the United States and Canada, 2nd edn. Johns Hopkins University Press, Baltimore, MD

Esque TC, Nussear KE, Drake KK, Walde AD and others (2010) Effects of subsidized predators, resource variability, and human population density on desert tortoise populations in the Mojave Desert, USA. Endang Species Res 12:167-177

Germano DJ (1994) Growth and age at maturity of North American tortoises in relation to regional climates. Can J Zool 72:918-931
Germano DJ, Joyner MA (1988) Changes in a desert tortoise (Gopherus agassizii) population after a period of high mortality. In: Szaro RC, Severson KE, Patton DR (eds) Management of amphibians, reptiles, and small mammals in North America. Proceedings of the Symposium. US Department of Agriculture, Forest Service, Fort Collins, CO, p 190-198

Germano J, Perry L (2012) Gopherus agassizii (desert tortoise) cohabitation with American badger. Herpetol Rev 43:127

Goodrich JM, Buskirk SW (1995) Control of abundant native vertebrates for conservation of endangered species. Conserv Biol 9:1357-1364

Jacobson ER, Gaskin JM, Brown MB, Harris RK and others (1991) Chronic upper respiratory tract disease of freeranging desert tortoises (Xerobates agassizii). J Wildl Dis 27:296-316

Lanszki J, Molnár M, Molnár T (2006) Factors affecting the predation of otter (Lutra lutra) on European pond turtle (Emys orbicularis). J Zool (Lond) 270:219-226

Ligon DB, Reasor J (2007) Predation on alligator snapping turtles (Macrochelys temminckii) by Northern river otters (Lontra canadensis). Southwest Nat 52:608-610

Longshore KM, Jaeger JR, Sappington JM (2003) Desert tortoise (Gopherus agassizii) survival at two eastern Mojave Desert sites: death by short-term drought? J Herpetol 37 : 169-177

> Lovich JE, Yackulic CB, Freilich J, Agha M and others (2014) Climatic variation and tortoise survival: has a desert species met its match? Biol Conserv 169: 214-224

Luckenbach RA (1982) Ecology and management of the desert tortoise (Gopherus agassizii) in California. In: Bury RB (ed) North American tortoises: conservation and ecology. US Department of the Interior, Fish and Wildlife Service, Washington, DC, p 1-37

Medica PA, Greger PD (2009) Gopherus agassizii (desert tortoise) predation by mountain lion. Herpetol Rev 40: 75-77

Medica PA, Nussear KE, Esque TC, Saethre MB (2012) Long-term growth of desert tortoises (Gopherus agassizii) in a Southern Nevada population. J Herpetol 46: $213-220$

Messick JP, Hornocker MG (1981) Ecology of the badger in southwestern Idaho. Wildl Monogr 76:3-53

Michener GR (2004) Hunting techniques and tool use by North American badgers preying on Richardson's ground squirrels. J Mammal 85:1019-1027

Minteer BA, Collins JP (2005) Ecological ethics: building a new tool kit for ecologists and biodiversity managers. Conserv Biol 19:1803-1812

Nagy KA, Medica PA (1986) Physiological ecology of desert tortoises in Southern Nevada. Herpetologica 42: 73-92

Osterback AMK, Frechette DM, Shelton AO, Hayes SA, Bond MH, Shaffer SA, Moore JW (2013) High predation on small populations: avian predation on imperiled salmonids. Ecosphere 4:art116

Peterson CC (1994) Different rates and causes of high mortality in two populations of the threatened desert tortoise Gopherus agassizii. Biol Conserv 70:101-108

Platt SG, Rainwater TR (2011) Predation by neotropical otters (Lontra longicaudis) on turtles in Belize. IUCN Otter Specialist Group Bulletin 28:4-10

> Rostal DC, Lance VA, Grumbles JS, Alberts AS (1994) Sea- 
sonal reproductive cycle of the desert tortoise (Gopherus agassizii) in the eastern Mojave Desert. Herpetol Monogr 8:72-82

Turner RM (1994) Mojave desertscrub. In: Brown DE (ed) Biotic communities, southwestern United States and northwestern Mexico. University of Utah Press, Salt Lake City, UT, p 157-168

Turner FB, Medica PA, Lyons CL (1984) Reproduction and survival of the desert tortoise (Scaptochelys agassizii) in Ivanpah Valley, California. Copeia 1984:811-820

Turner FB, Hayden P, Burge BL, Roberson JB (1986) Egg

Editorial responsibility: Matthew Hayward,

Bangor, UK production by the desert tortoise (Gopherus agaggizii) in California. Herpetologica 42:93-104

USFWS (US Fish and Wildlife Service) (1994) Desert tortoise (Mojave population) Recovery Plan. US Fish and Wildlife Service, Portland, OR

Woodbury AM, Hardy R (1948) Studies of the desert tortoise, Gopherus agassizii. Ecol Monogr 18:145-200

Zylstra ER, Steidl RJ, Jones CA, Averill-Murray RC (2013) Spatial and temporal variation in survival of a rare reptile: a 22-year study of Sonoran desert tortoises. Oecologia 173:107-116

Submitted: July 28, 2014; Accepted: May 12, 2015

Proofs received from author(s): July 7, 2015 